\title{
Research on Pattern and Motivation of Human Resources Management in Public Security Colleges
}

\author{
Liang $\mathrm{HU}^{1,2}$, Guang-wei ZHAO ${ }^{1}$, Jin $\mathrm{WEN}^{1}$, Hong-mei $\mathrm{Yu}^{1}$ \\ ${ }^{1}$ Department of Humanities and Management, Jiangxi Police College \\ Nanchang City, Jiangxi Province, P.R.China \\ ${ }^{2}$ Collaborative Innovation Center for Economics crime investigation and prevention technology \\ Jiangxi Province, P.R.China \\ huliang_thu@163.com
}

\begin{abstract}
Human resources are the driving force for the development of public security in colleges and universities in China. Under the increasingly fierce competitive environment, the traditional personnel management system can no longer meet the needs of the development of colleges and universities. Therefore, in view of the current situation of human resources in public security colleges, this paper puts forward the human resource management model, deepens the reform of the personnel distribution system, strengthens the performance assessment of human resources and improves the management level of human resources.
\end{abstract}

Keywords-Human resources management; Public security colleges; University teachers; Management pattern

\section{INTRODUCTION}

Since the establishment of the public security colleges and universities in the early 1980s, a large number of qualified and competent public security applied talents have been trained and transported to the public security team in China, which has made great contributions to the maintenance of national security and social stability. However, with the expansion of colleges and universities, the reform of the distribution system of public security institutions and the implementation of public examinations for public examinations, the public security colleges and universities are facing unprecedented challenges. In the face of the new situation, how to strengthen the management of human resources, improve the quality of human resources, strengthen the strength of running a school, and better cultivate high quality public security professionals for the society, is a serious problem that needs to be studied seriously.

The Chinese public security institutions have made some useful exploration to the reform of the personnel system, and have achieved certain results. But the contradiction between the traditional personnel management system and the needs of the development of public security education is becoming increasingly apparent. The level of human resources management and development in public security institutions still falls behind the other colleges and universities, and there are still a series of questions. The main problems are summed up in the following aspects.

\section{A. Administrative management pattern}

The management of personnel in public security institutions still stays in the traditional personnel management stage. As a human resource management department of public security institutions, the government departments still focus on work attendance, wages and personnel files, lack of understanding of the new theory of human resources management and lack of consciousness and ability to develop and manage human resources. At the same time, as a school leader, it is not aware of the importance of human resource management and development, and the lack of human resource management thought on the strategic level. It is believed that the development of the school is based on input, and the real bottleneck is lack of a high quality teaching staff and a lack of good work and life circle. China's police colleges and universities have a strong color of administration, which is also influenced by "official standard" thought, and administrative power is higher than academic power. Due to excessive interference in teaching and research activities, teachers' status should not be displayed, and teachers' enthusiasm for teaching and research is restricted.

\section{B. Imbalance of teachers pay gap}

The income of teachers in public security colleges, especially young teachers, has not yet reached the level of psychological expectation. In the whole society's income ranking, university teachers group is in the front position, but this is only based on the average income of university teachers. Because of the obvious polarization of the income of college teachers, the teachers' income is high in age, job title and high duty, while ordinary teachers, especially young teachers, have lower income, shorter working hours and lower income.

This is mainly manifested in the following aspects: first, equalitarianism in distribution. The wages, subsidies and bonuses of Public Security Colleges and universities are basically determined according to the regulations of the people's police and colleges and universities. They are not able to draw up the grade. Generally speaking, the treatment of high professional titles and high-level managers is obviously lower than the level of ordinary universities, and the treatment of low professional titles and general managers is higher than that of the juice, the role of performance assessment is not significant. Teacher incentive system also does not reflect the differences in Teachers' needs at different levels. Teachers of different ages 
and different titles have different demands on motivation. Young and middle-aged teachers have great pressure on life, more desire for material needs, and young and energetic, and eager for recognition and affirmation of career development.

\section{Imperfect performance evaluation system}

The fairness pursued by teachers must be complemented by scientific evaluation. In the human resource management of public security college teachers, the evaluation and evaluation system of teachers' performance is an important project, which requires a reasonable target system, a sound appointment system and a scientific assessment method. In reality, most public security colleges in China have actively established a set of scientific performance evaluation and assessment system, but there are still many problems in the implementation. First of all, in terms of teachers' incentive target system, they show heavy material needs and light spiritual needs. In the system of introducing teachers, they usually attract rich talents with generous salaries and generous policies. Secondly, the system of teachers' appointment is not sound enough. In the relevant regulations of the appointment system of teachers in China, it is clear that the appointment system of tenure is required. In practical operation, the post appointment of the public security college teachers is still a long and long way to go. Many public security colleges and universities have not broken the practice of lifelong appointment, and there is a situation that they can not enter and cannot get out. This indicates that the tenure system of appointment has not been truly implemented, and the corresponding elimination system is lacking. In a sense, this has affected the right of teachers to be fair. The poor performance of the people occupied the establishment of the school, and the excellent people did not have the opportunity to enter, making the public security college teachers lack of competition mechanism, affecting the enthusiasm of the teachers' work.

\section{Management of Teachers}

The survival and development of Public Security Colleges and universities depends on the quality of public security education and the quality of teachers in public security colleges. The school administrators manage the teachers with administrative instructions, only pay attention to the rationality and legality of the policy, but ignore the individual factors of the people, and can not give full play to the main role of the teachers in running school. Therefore, we must set up the concept of human resources development and management of "teacher oriented, talent first", speed up the transformation of traditional personnel management to human resource management in public security institutions. The work of school management and service departments is positioned to serve teachers and students, serve the teaching and research work of Teachers, and serve the teaching and scientific research personnel. The teacher team construction is included in the overall plan of the work, the teachers' structure is adjusted and perfected, the introduction mechanism of Teachers Facing the society and the open recruitment is set up, the reform of the teacher appointment system is accelerated, the teacher post classification management is carried out, the post appointment is strengthened, the flexible and varied flexible personnel mechanism is promoted, and the administrative tendency of teaching and scientific research is changed. Pay attention to the development of teachers' potential.

\section{COMPETENCY MODEL}

In 1973, Professor David, a psychologist at the Harvard University, published an article entitled "measurement of competence rather than intelligence" in the Journal of American psychologists. He cited a large number of research findings that explain the misuse of intelligence tests to judge the irrationality of individual abilities. Starting with first-hand materials, they directly excavate the personal and behavioral characteristics that can really affect the performance of the work and call it competency. From early 1999 to early 2000, the US Vivian consultants interviewed more than 130 top human resource practitioners from various sectors of the United States, and found that $40 \%$ of American companies had applied competency system management tools for more than 5 years or more, and $75 \%$ of the companies had applied victory capacity management tools for at least 2 years. Over $80 \%$ of senior managers, middle managers, executives and general management staff were included in the competency model. As the concept of competency is accepted and accepted by people in the world, more and more companies will use competency model to develop and manage human resources effectively.

The basic principle of competency model construction is to distinguish the differences between the excellent members and the general members in the knowledge, skills, social roles, self cognition, characteristics, motivation and so on. By collecting and analyzing the data and integrating the data scientifically to establish a model framework for the competency of a job, and then the production of the competency model. The corresponding human resource management system is operable. There are a lot of competence characteristics of a member, but what the organization needs is not necessarily all of their competence. The organization will determine the competency that can make members competent for the job and ensure their maximum potential, according to the requirements of the post and the environment of the organization. It is necessary to use competency model analysis to extract competency that can predict employees' work better. 
TABLE I.

COMPETENCY MODEL

\begin{tabular}{|c|l|}
\hline Property & \multicolumn{1}{c|}{ Description } \\
\hline Skill & The ability to learn and apply technical expertise, such as the ability to use the text, the ability to operate the computer. \\
\hline Social Role & Individual cognition and understanding of social relations, as of the relationship with the leader. \\
\hline Self-cognition & Perception and evaluation of one's identity, such as the understanding of their proficiency in a particular line. \\
\hline Trait & The characteristic or typical behavior of a person, as good at communication and expression. \\
\hline Motivation & The idea or idea of determining the inherent stability of an explicit act, as of the pursuit of interests. \\
\hline
\end{tabular}

The competency model describes the results of the analysis that distinguishes the high performance from the general or low performance, and summarizes what the skills, knowledge, and personality characteristics are needed to complete the work, and which behavior is the most influential to the performance and the achievement of the work. This technology is more reliable than the traditional job description which often ignores knowledge and skills.

The general process of building up the competency model is as follows:

Step 1: Selected research positions.

Step 2: Study the performance standard of the position.

Step 3: Analyze major tasks.

Step 4: Acquire data about competency of the sample.

Step 5: Collect information and establish a preliminary model.

Based on the quality model, the current compensation system of Public Security Colleges and universities is reformed. Based on the competence, different salary structures should be designed for the members of different competence. This is beneficial for teachers to improve their knowledge and ability, to promote the improvement of human resources quality, to break the strict official standard malpractice of the traditional post grade division; to establish a category suitable for the public security system, teachers can no longer gain a substantial increase in remuneration through the promotion of the post, and can also improve their knowledge and skills. Or the increase in the ability to obtain remuneration reflects the respect for its personality and creativity, and makes them continuously improve their existing knowledge and skill level with managers at all levels, continue to play their own advantages, and effectively support the cultivation of the core competitiveness of the public security teachers. Applying the competency analysis to the performance management of public security institutions, we should balance the teachers' contributions and individual competence development, the current value and the long-term development, short-term performance and long-term goals of the organization, and evaluate the three aspects of the completion of the target, the improvement of the performance and the ability to win the responsibility.

The introduction of this model to the public security institutions in China provides a new perspective for the development and management of human resources. It will help break the old and rigid personnel management system, combine the personal competence of the teachers with the organizational goals of the public security team, and improve the incentive effect of the human resources management of the public security school and realize the public.

\section{DISCUSSION AND FUTURE WORK}

College teachers are the first resources in Colleges and universities. It is the key to enhance the competitiveness of colleges and universities. The effective management of teachers' human resources is very important to colleges and universities. The existing human resources management and development mode in public security colleges and universities can not meet the needs of the development of public security education. The public security colleges and universities should analyze the teachers' needs and draw lessons from the experience of human resource management in ordinary colleges and universities. On this basis, the construction plan of the incentive mechanism of college teachers should be put forward to form the human resources with the characteristics of public security institutions.

\section{ACKNOWLEDGMENT}

This author's work is supported by JiangXi Science and Technology Research Project of Education Department (GJJ151193), JiangXi University Party Building Project (16DJQN065), JiangXi Police College Scientific Research Project (2016JGZB008) and JangXi Science Education Planning Project (17YB244).

This author's work also is supported by the Opening Project of Collaborative Innovation Center for Economics crime investigation and prevention technology, Jiangxi Province.

\section{REFERENCES}

[1] Li Xinyu. Reflections on the construction of teaching staff in public security colleges[J]. Public security education, 2011 (1). (In Chinese)

[2] Liu Ning. On the improvement and innovation of the incentive mechanism of college teachers[J]. Vocational education research, 2012. (In Chinese)

[3] $\mathrm{Xu}$ Yongjin. The improvement and enhancement of the incentive mechanism for university teachers [J]. China's higher education research, 2005. (In Chinese)

[4] Zhao Fuqiang. Optimization of talent training mode of international human resource management in universities $[\mathrm{J}]$. Contemporary economic management, 2018,40 (02): 66-71. (In Chinese)

[5] Song Junfeng. A strategy for the incentive mechanism of human resources management in university teachers [J]. Chinese adult education, 2014, 24: 39-41. (In Chinese)

[6] Li Jun. Research on human resource management in Chinese universities [J]. Finance and finance, 2010 (04): 69-71. (In Chinese)

[7] Li Min. The current situation and Countermeasures of human resource management in Colleges and universities[J]. Education and occupation, 2008 (20): 39-40. (In Chinese) 